\title{
圈/ QUEEN'S UNIVERSITY BELFAST

\section{Dynamic Modelling and Performance Prediction of a Multi-unit Baseline Air Conditioning System for a Generic Bus under Part-Load Conditions}

Afrasiabian, E., Douglas, R., \& Best, R. (2021). Dynamic Modelling and Performance Prediction of a Multi-unit Baseline Air Conditioning System for a Generic Bus under Part-Load Conditions. SAE International Journal of Commercial Vehicles, 14(2), [02-14-02-0015]. https://doi.org/10.4271/02-14-02-0015

Published in:

SAE International Journal of Commercial Vehicles

Document Version:

Peer reviewed version

Queen's University Belfast - Research Portal:

Link to publication record in Queen's University Belfast Research Portal

Publisher rights

Copyright 2021, SAE International.

This work is made available online in accordance with the publisher's policies. Please refer to any applicable terms of use of the publisher.

\section{General rights}

Copyright for the publications made accessible via the Queen's University Belfast Research Portal is retained by the author(s) and / or other copyright owners and it is a condition of accessing these publications that users recognise and abide by the legal requirements associated with these rights.

Take down policy

The Research Portal is Queen's institutional repository that provides access to Queen's research output. Every effort has been made to ensure that content in the Research Portal does not infringe any person's rights, or applicable UK laws. If you discover content in the

Research Portal that you believe breaches copyright or violates any law, please contact openaccess@qub.ac.uk. 


\title{
Dynamic modelling and performance prediction of a multi-unit baseline air conditioning system for a generic bus under part-load conditions
}

\author{
Ehsan Afrasiabian, ${ }^{1}$ Roy Douglas, ${ }^{1}$ and Robert Best ${ }^{2}$ \\ ${ }^{1}$ Queen's University Belfast, UK \\ ${ }^{2}$ Wrightbus, UK
}

\begin{abstract}
A dynamic model of a multi-unit air conditioning system in a generic bus was developed to investigate different control strategies on the system performance and the cabin comfort level. In this study, a part-load condition was considered, where adopting a proper strategy for governing a multi-unit system is important. Simulink and Simscape toolbox from MATLAB (R2019a) were used to build up the real-time model by integrating a cooling system with a cabin sub-model. The cooling system consists of two independently controlled units, based on a Vapour Compression Cycle (VCC). The cabin is modelled using a moisture air network and is coupled with the cooling system to exchange heat with the refrigerant through the evaporators. Moreover, the sensible and latent loads are incorporated into the cabin by a thermal network. Six different strategies were implemented using different criteria, to investigate the average power and COP (Coefficient of Performance) under a part-load condition. The comfort level was obtained in terms of the Predicted Mean Vote (PMV) and Predicted Percentage of Dissatisfied (PPD) indices. Results are suggestive of a link between the implemented control strategy of a multi-unit AC system and its performance. Results showed that five out of the six proposed strategies might be chosen, depending on the adopted trade-off policy between the comfort level and the system energy demand. In this way, the numerical approach introduced here along with the combination of the presented findings, provide a good support for the decision-making on thermal management inside the cabin, based on the energy consumption and the thermal comfort level.
\end{abstract}

Keywords: Air Conditioning in Buses, Refrigeration Cycle, Thermal Comfort, MATLAB, Simulink

\section{Introduction}

Air conditioning (AC) systems in Electric Vehicles (EV), where the energy storage capacity is limited, may potentially be energy-sucking devices reducing their driving range. For AC in EVs, it is therefore important to reduce energy consumption by adopting more efficient and innovative system architectures, components and/or control strategies.

In recent years, various studies have been conducted on the AC functionality and thermal comfort, mostly for buildings [1] or passenger cars $[2,3,4,5]$, while very little research has been published on buses [6, 7, 8]. On top of that, these studies can be categorized into two main groups based on whether the emphasis is on the cooling system or just indoor space. In fact on one hand, some studies have emphasized the thermal modelling of indoor/cabin spaces trying to evaluate the thermal loads and the comfort condition by means of detailed CFD (Computational Fluid Dynamics) [5, 9, 10, 11] or lumped-parameter models. For example, Marcos et al. [2] developed a thermal model of the cabin in passenger vehicles using Simulink-MATLAB. Fayazbakhsh et al. [12] applied the heat balance method and a lumped-body approach, to estimate the heating and cooling loads in a specific passenger vehicle. Modares et al. [13] investigated the comfort level in a passenger vehicle by dynamic modelling of thermal loads inside the cabin. Torregrosa-Jaime et al. [14] also proposed a dynamic lumped-parameter model to calculate both the sensible and latent thermal loads of a minibus' multi-zone cabin. Lee et al. [15] developed a lumped-parameter model to investigate the dynamic behaviour of cabin thermal conditions. Then they evaluated a mobile air conditioning design by incorporating the vapour compression cycle concept into the cabin model. 
On the other hand, some researchers focused on refrigeration cycles for cooling systems in residential/commercial buildings or automotive applications. For instance, Kiss et al. [16] evaluated the transient total power requirement of the AC system from engine or energy storage systems on the MATLAB/Simulink platform. They presented a model of zero-dimensional (0D) volume blocks, connected by 1D pipe blocks in the refrigerant side, while the cabin load was modelled by a $0 \mathrm{D}$ lumped-sum block to provide a proper thermal boundary condition for the refrigerant cycle. They mainly focused on the thermodynamic state of the refrigerant and the cooling system performance. Huang et al. [17] developed a dynamic model based on a lumped parameter method to investigate the optimal energy-saving control of automotive air conditioning and refrigeration systems. In their model, the AC system was turned on whenever the temperature of the cargo space was within the upper and lower bands around a set-point temperature. Schaut and Sawodny [18] adopted a predictive and optimization-based approach for the thermal management of a passenger vehicle cabin. Their model involved lumped parameter cabin sub-model and HVAC system, where the latter one was represented by a resistance heater (heating mode)/evaporator (cooling mode), and a blower to adjust the heating/cooling power and airflow rate entering the cabin.

In this paper, a real-time model was built up by coupling two sub-models (AC and Cabin) on the Simscape platform within the Simulink environment. The AC system here is multi-unit where each unit could be controlled independently. The AC units operate based on the Vapour Compression Cycle (VCC), interacting (two-way) with the cabin and ambient through their evaporators and condensers. R134a is the refrigerant chosen to undergo different thermodynamic states due to the compressor's work, expansion, and heat transfer with the moist air coming from the ambient and the cabin. Then this model was applied to predict the thermal condition, discomfort level, and required power by the AC system under different control strategies, based on the set-point temperature and/or Discomfort Index (DI) criteria. Together with the presented results, the numerical approach applied here provide a good basis for decision-making on thermal management within the cabin by assessing the energy consumption and thermal comfort.

\section{Methodology}

In this study, Simscape toolbox and Simulink from MATLAB (R2019a) were used to build up a baseline AC model for a generic bus. Simscape provides multi-domain blocks for creating physical sub-models that can be integrated to build up more complex master-models. In fact, each block represents a set of mathematical equations associated with a certain physical event. These blocks could be connected via physical lines carrying information between them during the simulation and blocks evaluation. Here three physical networks were coupled, namely: Two-Phase, Moist Air, and Thermal networks to create a coupled master-model including a refrigeration cycle of a multi-unit AC system and the cabin of a generic bus, as shown in Fig. 1 - 4. Different physical components of the system and networks were represented by either pre-defined blocks from the Simscape/Simulink libraries or user-defined functions.

\subsection{VCC sub-model}

The Two-Phase network was used to establish a cooling cycle with R134a flow as the phase-changing refrigerant in the AC units, as illustrated in Fig. 2 and Fig. 3. Each AC unit operates based on a conventional refrigeration cycle and is mainly composed of an evaporator, accumulator, compressor, condenser, and an expansion valve. Heat is taken from the cabin by the evaporators and then is released to the ambient through the condensers. Each unit and its respective blower and fan operate independently, based on the adopted control strategy.

Evaporator/Condenser: Both the evaporator and condenser are air-to-refrigerant heat exchangers where a liquid-vapor phase change takes place on the refrigerant side. A two-phase flow enters the evaporator, after passing through an expansion valve, takes the heat from the cabin and becomes super-heated before going to an accumulator. This heat is then released into the ambient through the condenser. Here the evaporators and condensers are generic heat exchangers from the Two-Phase library of Simscape (R2019a), where the main geometrical parameters such as the number of tubes rows perpendicular to the airflow direction $\left(N_{\text {row }}\right)$, number of tubes turns in each row $\left(N_{t u}\right)$, tubes diameter $\left(d_{\text {tube }}\right)$, height and width of the heat exchanger $(L \times L)$, and the fins surface area $\left(S_{\text {fin }}\right)$ are listed in Table 1. This is a multi-domain block with a three-zone refrigerant side and moist airside, where depending on the operating conditions condensation on the airside might occur as well. 
It is important to stress that, the Simscape library has been well established and a full discussion of the governing equations associated with the adopted blocks lies beyond the scope of this study. For further theoretical and numerical details, please see MATLAB documentation [19].

Electronic Expansion Valve (EEV): Here, a controlled variable local restriction was adopted to represent an EEV. The restriction area changes to adjust the super-heat degree at the outlet of the evaporator. The refrigerant mass flow rate $\left(\dot{m}_{r}\right)$ is a function of the valve discharge coefficient $\left(C_{D}\right)$ that reflects the pressure loss through the restriction area and the ideal mass flow rate $\left(\dot{m}_{\text {Ideal }}\right)$ as:

$$
\dot{m}_{r}=C_{D} \cdot \dot{m}_{\text {ideal }}
$$

Compressor: In this model, the compressor block is a controlled mass flow rate source that increases the pressure and temperature of the low-pressure super-heated refrigerant. The refrigerant flow rate through the compressor is governed by:

$$
\dot{m}_{r}=\eta_{v} \cdot \rho_{r, s u c} \cdot \dot{V}_{\text {comp }}
$$

where $\dot{V}_{\text {comp }}$ is the displacement volume of the compressor, $\eta_{v}$ is the volumetric efficiency, and $\rho_{r, s u c}$ is the refrigerant (R134a) density at the suction line.

Accumulator: As depicted in Fig. 3, to prevent liquid droplets of the R134a flow from entering the compressor an accumulator was placed before the compressor suction side to make sure the compressor can serve its purpose efficiently and safely. A two-phase receiver accumulator from the Simscape library was adopted where the liquid refrigerant accumulated inside and just the vapour passed to the compressor, unless the container was fully liquid.

Fans and Blowers: To circulate the air inside the cabin and through the evaporator of each unit to treat its sensible and latent loads a blower was adopted. Likewise, to blow the ambient air through the condenser of each unit in order to remove the heat from the super-heated refrigerant a fan was applied. In the current study, the controlled volumetric flow rate source was used to model the moist air flow rate through the condensers and evaporators.

\subsection{Cabin sub-model and Thermal loads}

The passengers' cabin was modelled as a zero-dimensional constant volume chamber with the in/outlet ports for the circulated moist air through the evaporators, and allocated vent to the ambient, as illustrated in detail in Fig. 2 and Fig. 4. The cabin is linked with the associated thermal loads and coupled with the VCC sub-model (via evaporators). As implied by Fig. 4, in this study and for the sake of simplicity we reduced the bus geometry into a four-sided geometry consisting of a top, floor, windows, and side surfaces. Each surface is represented by a thermal node where heat flows through or can be stored inside. Here the general energy equation of the illustrated thermal network in Fig. 4 includes the heat stored by the thermal mass $\left(\dot{Q}_{\text {mass }}\right)$, the solar radiation $\left(\dot{Q}_{s o l}\right)$, passenger heat generation $\left(\dot{Q}_{m e t}\right)$, and heat transfer through convection/conduction between inside the cabin and the ambient $\left(\dot{Q}_{a m b}\right)$ that reads as:

$$
\begin{aligned}
\dot{Q}_{\text {mass }}+\rho_{a} \cdot V_{c a b} \cdot c_{p, a} \cdot \frac{d T_{c a b}}{d t} & =\dot{Q}_{s o l}+\dot{Q}_{a m b}+\dot{Q}_{m e t}+\dot{Q}_{v e n t}+\dot{Q}_{\text {engine }}+\dot{Q}_{A C} \\
\dot{Q}_{\text {sol }} & =\dot{Q}_{\text {sol,ext }}+\dot{Q}_{\text {sol,int }} \\
\dot{Q}_{\text {sol,ext }} & =\sum_{i=\text { top }, \text { side,win }} I_{a v}^{\prime} \cdot \tau_{i} \cdot S_{i} \\
\dot{Q}_{\text {sol,int }} & =I^{\prime}{ }_{\text {av }} \cdot \alpha_{\text {win }} \cdot \tau_{\text {int }} \cdot S_{\text {win }}
\end{aligned}
$$

where, $I^{\prime}{ }_{a v}$ is the average solar irradiance, $\tau$ stands for the absorptivity coefficient, and $\alpha$ represents the transmissivity coefficient. Here $S_{\text {side }}$ and $S_{\text {win }}$ account for $1 / 2$ of the total peripheral surface areas of the bus body and windows that receive the solar radiation, respectively. Here the solar thermal load absorbed by the external body is introduced by $\dot{Q}_{s o l, e x t}$, and the part which passes through the windows and gets absorbed inside 
the bus is represented by $\dot{Q}_{\text {sol,int }}$. In this study the ventilation $\left(\dot{Q}_{\text {vent }}\right)$ and engine $\left(\dot{Q}_{\text {engine }}\right)$ loads are assumed negligible. Moreover, the sensible and latent loads generated by the passengers are defined as:

$$
\begin{gathered}
\dot{Q}_{\text {met }, s}=N_{\text {pas }} \cdot A_{\text {pas }} \cdot M_{s} \\
\dot{Q}_{\text {met }, l}=N_{\text {pas }} \cdot M_{l}
\end{gathered}
$$

In this study, $A_{\text {pas }}=1.8\left(\mathrm{~m}^{2}\right)$ is the average surface area of a typical body, $M_{s}=70\left(\mathrm{~W} / \mathrm{m}^{2}\right)$ and $M_{l}=2.58$. $10^{-5}(\mathrm{~kg} / \mathrm{s}) h_{l}$ are the sensible and latent metabolic rates of one typical passenger, respectively [20, 21]. The cooling capacity of the AC unit reads as:

$$
\dot{Q}_{A C}=\dot{m}_{r} \cdot\left(h_{e, r, o u t}-h_{e, r, \text { in }}\right)
$$

In Eqs. (3) and (4), $h_{e, r}$ stands for the specific enthalpy of R134a and $h_{l}$ is the latent heat of condensation of water vapor. The whole thermal network including the above mentioned loads is illustrated in Fig. 4 while the governing equations for the thermal mass $\left(\dot{Q}_{\text {mass }}\right)$, convection $\left(\dot{Q}_{c o n v}\right)$, and conduction $\left(\dot{Q}_{c o n d}\right)$ heat transfer blocks (with two ports; A and B) are as follows:

$$
\begin{gathered}
\dot{Q}_{\text {mass }}=m \cdot c_{p} \cdot \frac{d T}{d t} \\
\dot{Q}_{c o n v}=k_{c o n v} \cdot S \cdot\left(T_{B}-T_{A}\right) \\
\dot{Q}_{C o n d}=k_{\text {cond }} \cdot S \cdot\left(T_{B}-T_{A}\right) / L
\end{gathered}
$$

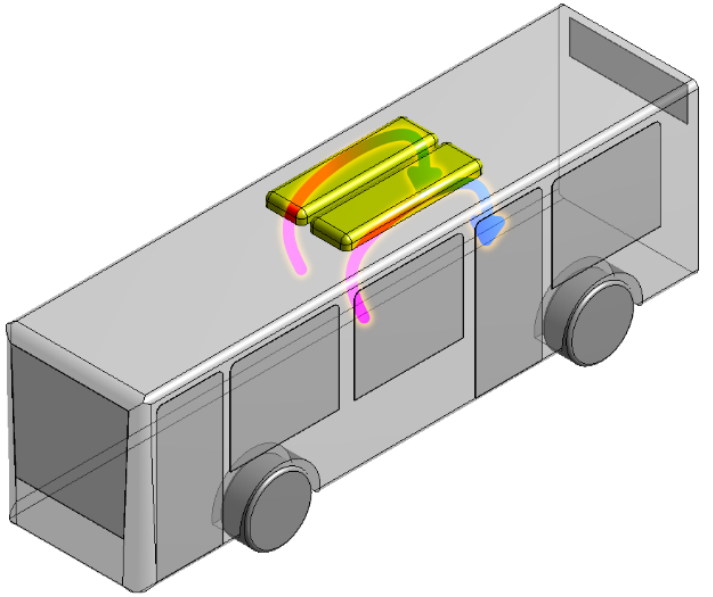

Fig. 1: Schematic of the multi-unit AC system and the bus cabin.

\begin{tabular}{|c|c|c|c|c|c|c|c|c|}
\hline \multicolumn{3}{|c|}{ Cabin's parameters } & $\alpha_{\text {win }}$ & \multicolumn{2}{|l|}{0.36} & \multicolumn{3}{|c|}{ AC System's Parameters } \\
\hline$c_{p, b, \text { ext }}$ & 1400 & $J . \mathrm{kg}^{-1} \cdot \mathrm{K}^{-1}$ & $\tau_{b, \text { ext }}$ & 0.45 & & $d_{\text {tube,c }} \& d_{\text {tube }, e}$ & 0.01 & $m$ \\
\hline$c_{p, b, i n t}$ & 1000 & & $\tau_{b, \text { int }}$ & 1 & & $L_{c} \& L_{e}$ & 0.85 & \\
\hline$c_{p, \text { win }}$ & 840 & & $\tau_{\text {win }}$ & 0.16 & 22] & $N_{\text {row }, c} \& N_{\text {row }, e}$ & 30 & \\
\hline$k_{\text {cond }, b}$ & 0.20 & $W \cdot m^{-1} \cdot K^{-1}$, & Operatin & g Conc & lition & $N_{t u, c} \& N_{t u, e}$ & 6 & \\
\hline$k_{\text {cond,win }}$ & 0.75 & & $I_{a v}^{\prime}$ & 800 & $W \cdot m^{-2}$ & $S_{f i n, c} \& S_{f i n, e}$ & 32 & $m^{-2}$ \\
\hline$m_{b, e x t+w i n}$ & 8500 & $\mathrm{~kg}$ & $k_{\text {conv, ext }}$ & 20 & $W \cdot m^{-2} K^{-1}$, & $\dot{V}_{\text {comp }}$ & 17.1 & $m^{-3} \cdot h r^{-1}$ \\
\hline$m_{b, \text { int }}$ & 3000 & & $k_{\text {conv,int }}$ & 5 & & $\dot{V}_{f} \& \dot{V}_{b l}$ & 3600 & $m^{-3} \cdot s^{-1}$ \\
\hline$S_{\text {top }}$ & 25 & $m^{2}$, & $N_{\text {pas }}$ & 22 & & $W_{f} \& W_{b l}$ & 250 & $W$ \\
\hline$S_{\text {floor }}^{\text {cop }}$ & 25 & & $R H_{a m b}$ & 25 & $\%$ & $\eta_{v}$ & 0.8 & \\
\hline$S_{\text {side }}$ & $18.75^{*}$ & & $R H_{\text {initial }}$ & 50 & & & & \\
\hline$S_{\text {win }}$ & $18.75^{*}$ & & $T_{A m b}$ & 35 & ${ }^{\circ} \mathrm{C}$, & & & \\
\hline
\end{tabular}

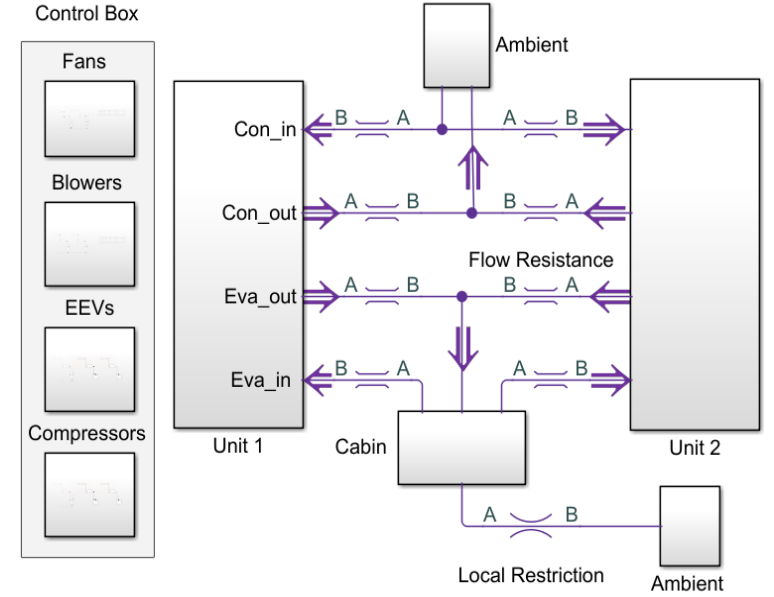

Fig. 2. The AC system architecture. Air flow is colored in purple.

For the current study, the operating conditions and adopted parameters of the cabin and the AC system are listed in Table 1.

Table 1. Adopted parameters in the model 


\begin{tabular}{llll}
$V_{\text {cab }}$ & $75, \quad \mathrm{~m}_{\text {cab,initic }}, \quad \begin{array}{l}* 1 / 2 \text { of the total surface area around } \\
\text { the bus. }\end{array}$ \\
\hline
\end{tabular}

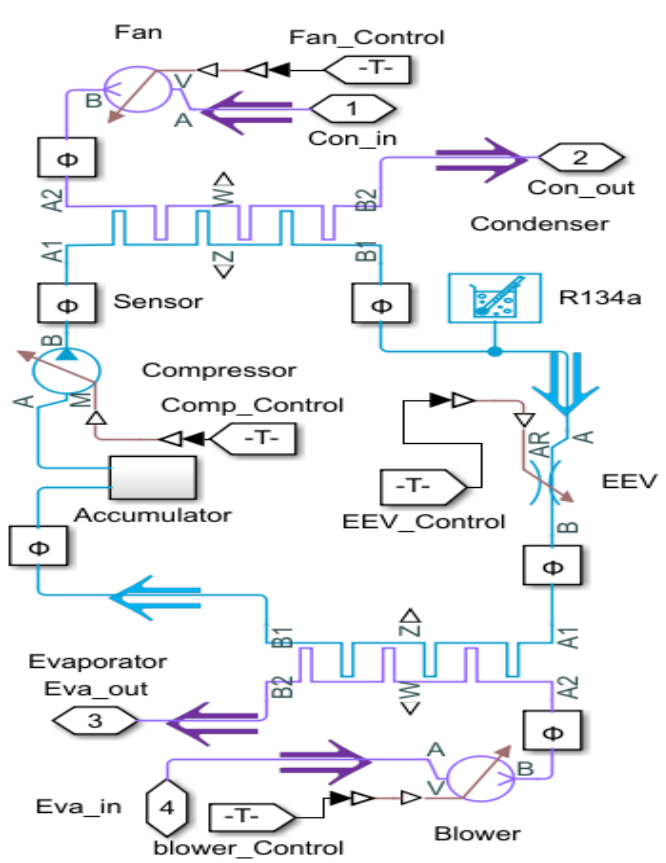

Fig. 3: Schematic of one AC unit. Blue and purple lines represent the refrigerant and moist air, respectively.

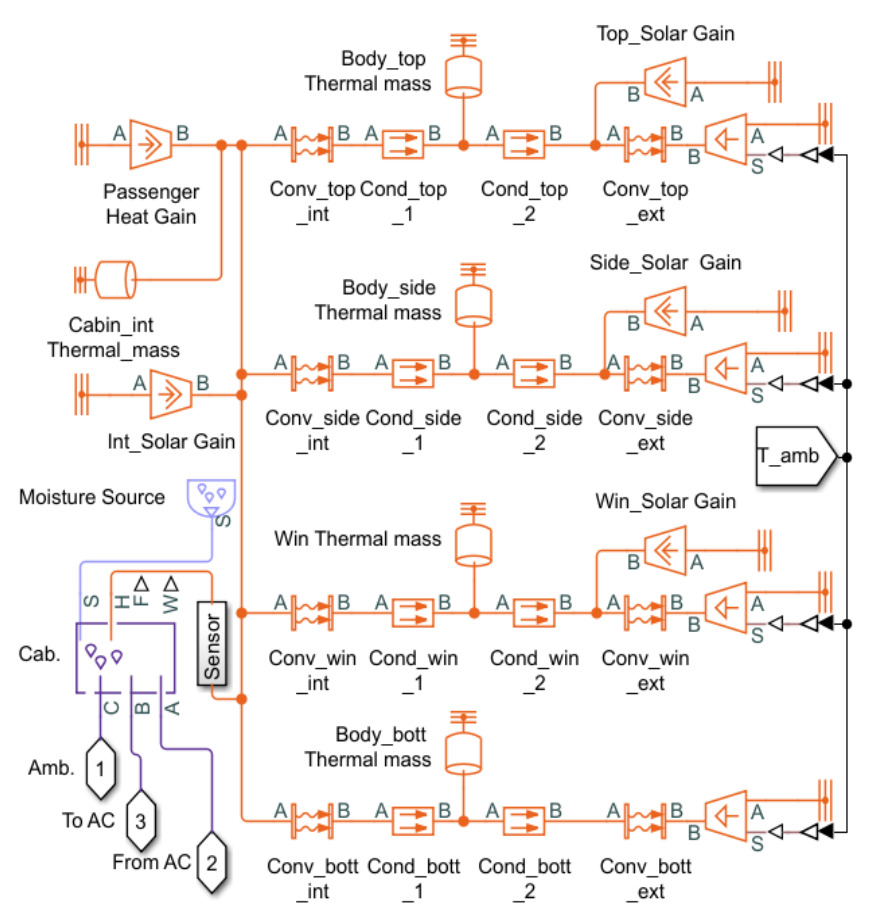

Fig. 4. Sensible (in orange) and latent (in light purple) thermal networks incorporated into the cabin (in Purple).

\section{Control strategy}

The AC system here is composed of two cooling units, each one operates independently to meet the required criteria. In this study, we investigated the overall performance of the system to control two comfort intuitive parameters, temperature and humidity inside the cabin. Here, two main approaches were adopted, based on; i) the set-point temperature $\left(T_{\text {set }}=25^{\circ} \mathrm{C}\right)$ or ii) Discomfort Index (DI). In the first one, the AC units operated to keep the cabin temperature $\left(T_{c a b}\right)$ within an upper $\left(T_{u}=T_{\text {set }}+\Delta T\right)$ and lower $\left(T_{l}=T_{\text {set }}-\Delta T\right)$ thresholds. In the second approach DI, which is widely used to evaluate the thermal discomfort level in out/indoor spaces $[23,24]$, was adopted as a practical criterion only for the control purpose as:

$$
D I=T_{c a b}-0.55(1-0.01 R H)\left(T_{c a b}-14.5\right)
$$

DI here is a linear function of the cabin temperature $\left({ }^{\circ} \mathrm{C}\right)$ and relative humidity (\%), categorized into six zones ranges from $D I<21^{\circ} \mathrm{C}$ (no discomfort) to $31^{\circ} \mathrm{C}<D I$ (state of medical emergency). In this study, the acceptable zone for discomfort index was when $21^{\circ} \mathrm{C}<D I<24{ }^{\circ} \mathrm{C}$, where less than $50 \%$ of passengers would feel discomfort. These approaches would be based on the data from the cabin's temperature and humidity sensors so that the valves, compressors, fans, and blowers could be governed accordingly. In the current model and for each unit, when the compressor went off, both the respective fan and blower went off and the EEV was closed as well. In this way, we investigated different control strategies as listed in Table 2.

Table 2: Adopted control strategies of the AC system with different control criteria

\begin{tabular}{llllc}
\hline Strategy & Unit 1 Off if: & Unit 1 On if: & Unit 2 Off if: & Unit 2 On if: \\
\hline$S 1$ & $T_{c a b}<23^{\circ} \mathrm{C}$, & $27^{\circ} \mathrm{C}<T_{c a b}$, & $\mathrm{N} / \mathrm{A}$ & $\mathrm{N} / \mathrm{A}$ \\
$S 2$ & $T_{c a b}<23^{\circ} \mathrm{C}$, & $27^{\circ} \mathrm{C}<T_{c a b}$, & $D I<21^{\circ} \mathrm{C}$, & $24^{\circ} \mathrm{C}<D I$ \\
$S 3$ & $T_{c a b}<23^{\circ} \mathrm{C}$, & $27^{\circ} \mathrm{C}<T_{c a b}$, & $T_{c a b}<23^{\circ} \mathrm{C}$, & $27^{\circ} \mathrm{C}<T_{c a b}$ \\
$S 4$ & $D I<21^{\circ} \mathrm{C}$, & $24^{\circ} \mathrm{C}<D I$, & $D I<21^{\circ} \mathrm{C}$, & $24^{\circ} \mathrm{C}<D I$ \\
$S 5$ & $T_{c a b}<24^{\circ} \mathrm{C}$, & $26^{\circ} \mathrm{C}<T_{c a b}$, & $T_{c a b}<24^{\circ} \mathrm{C}$, & $26^{\circ} \mathrm{C}<T_{c a b}$ \\
$S 6$ & $T_{c a b}<24^{\circ} \mathrm{C}$, & $26^{\circ} \mathrm{C}<T_{c a b}$, & $T_{c a b}<23^{\circ} \mathrm{C}$, & $27^{\circ} \mathrm{C}<T_{c a b}$ \\
\hline
\end{tabular}

In these scenarios, the control criteria are based on either the cabin temperature $\left(T_{c a b}\right)$, DI, or both, as listed in Table 2. For example in the first scenario (S1), just one unit operated to keep $T_{c a b}$ within the temperature thresholds $\left(T_{\text {set }} \pm 2^{\circ} \mathrm{C}\right)$, while in $\mathrm{S} 2$ a combined strategy was implemented as one unit worked based on the 
temperature thersholds $\left(T_{\text {set }} \pm 2^{\circ} \mathrm{C}\right)$ and the other one functioned to maintain the DI within the acceptable range $\left(21^{\circ} \mathrm{C}<D I<24{ }^{\circ} \mathrm{C}\right)$. In S3 and $\mathrm{S} 4$, both units operated simultaneously in accordance with the temperature thresholds $\left(T_{\text {set }} \pm 2^{\circ} \mathrm{C}\right)$ and the acceptable range for DI, respectively. In S5 the temperature margin was reduced to $\Delta T=1^{\circ} \mathrm{C}$, then both units worked together on the basis of a narrower temperature range $\left(T_{\text {set }} \pm 1^{\circ} \mathrm{C}\right)$. Finally, in S6 both units functioned to keep $T_{c a b}$ within different temperature thersholds, namely $T_{\text {set }} \pm 1^{\circ} \mathrm{C}$ for the first unit and $T_{\text {set }} \pm 2^{\circ} \mathrm{C}$ for the second one.

\section{Results and Discussion}

\subsection{Validation}

The CoolPack toolkit (V1.5) was used to validate the VCC model. CoolPack is a widely-used industry standard refrigeration toolset for designing, sizing, and analysing the refrigeration systems, that consists of three main simulation programs namely: Refrigeration Utility, EES Cool Tool (as an Engineering Equation Solver), and Dynamic Analysis Tool. We validated the current model against the results from CoolPack, under different condenser's and evaporator's temperatures $\left(T_{c}, T_{e}\right)$. The absorbed heat by the evaporator from the cabin $\left(Q_{e}\right)$ and COP (Coefficient of Performance) of the system (including the fans' and blower's power) were compared to make sure the cooling capacity at the interface with the cabin network and the thermodynamic states for the refrigerant (R134a) are valid. All the data from the MATLAB model were compared with the CoolPack when the refrigerant exited the evaporator with super-heating degree $\Delta T_{\text {sup }}=2{ }^{\circ} \mathrm{C}$ and entered the expansion valve as a saturated liquid with sub-cooling degree $\Delta T_{\text {sub }}=0^{\circ} \mathrm{C}$, as the minimum acceptable value. Fig. 5 and Fig. 6 show that for a single unit AC system with the specifications listed in Table 1 and above-mentioned assumptions, the current model can predict the removed heat from cabin and the performance of the system very well with less than $1 \%$ error.

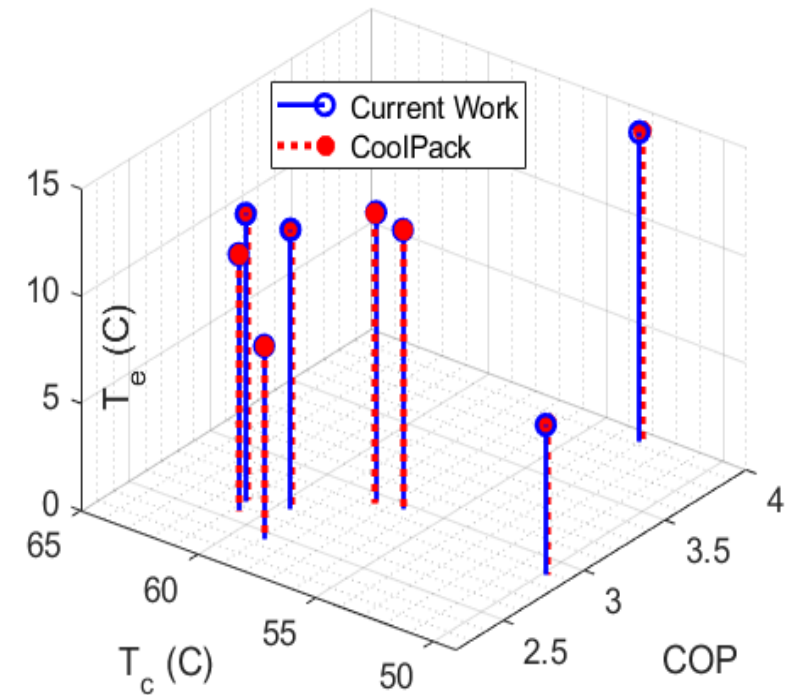

Fig. 5: COP of the AC system (single unit); current model vs. CoolPack.

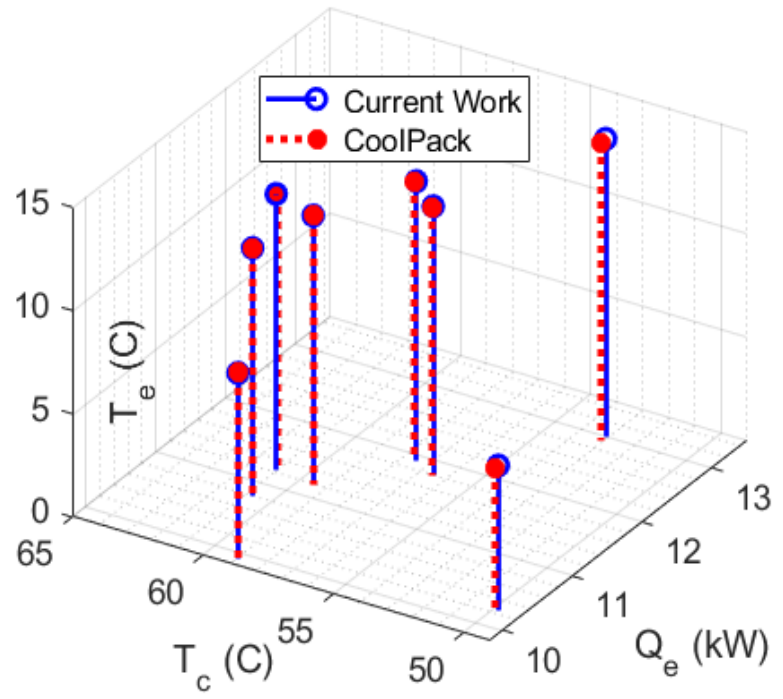

Fig. 6: Absorbed heat by the evaporator of the AC system (single unit) from the cabin $\left(Q_{e}\right)$; current model vs. CoolPack.

\subsection{Thermal comfort analysis}

To keep the balance between the energy cost for air conditioning and the discomfort (comfort) level, it is important to quantify the discomfort level. DI here was employed as a practical way to control the AC units, based on the sensible parameters $(T, R H)$; however, more elaborate indices were adopted to evaluate the comfort condition, namely PMV (Predicted Mean Vote) and PPD (Predicted Percentage of Dissatisfied). PMV and PPD are two widely accepted and used indices to analyse the thermal comfort for occupants in indoor spaces [25]. PMV gives the predicted mean vote of a large group of people on the thermal sensation and is a non-linear function of the average metabolic rate $(\mathrm{M})$, effective mechanical power $(W)$, and the heat exchange rates between the body and its surrounding through different mechanisms. In the same vein, PPD predicts the expected percentage of dissatisfied people under the given thermal conditions in terms of PMV as:

$$
P P D=100-95 \cdot \exp \left(-\left(0.03353 \cdot P M V^{4}+0.2179 \cdot P M V^{2}\right)\right)
$$




$$
\begin{aligned}
& P M V=(0.303\cdot \exp (-0.036 . M)+0.028) \cdot\left((M-W)-3.05 \cdot 10^{-3} .\right. \\
& \cdot\left(5733-6.99 \cdot(M-W)-p_{v a}\right)-0.42 \cdot((M-W)-58.15)-1.7 \cdot 10^{-5} \\
& \cdot M\left(5867-p_{v a}\right)-0.0014 \cdot M \cdot\left(34-T_{a}\right)-3.96 \cdot 10^{-8} \cdot f_{c l} \\
&\left.\cdot\left(\left(T_{c l}+273\right)^{4}-\left(\bar{T}_{r}+273\right)^{4}\right)-f_{c l} \cdot k_{c o n v} \cdot\left(T_{c l}-T_{a}\right)\right) \\
& T_{c l}=35.7-0.028 \cdot(M-W)-I_{c l} \cdot \\
& \cdot\left(3.96 \cdot 10^{-8} \cdot f_{c l} \cdot\left(\left(T_{c l}+273\right)^{4}-\left(\bar{T}_{r}+273\right)^{4}\right)+f_{c l} \cdot k_{c o n v} \cdot\left(T_{c l}-T_{a}\right)\right)
\end{aligned}
$$

and

$$
\begin{aligned}
& k_{\text {conv }}= \begin{cases}2.38 \cdot\left|T_{c l}-T_{a}\right|^{0.25} & \text { if } \quad 2.38 \cdot\left|T_{c l}-T_{a}\right|^{0.25} \geq 12.1 \cdot \sqrt{v_{a r}} \\
12.1 \cdot \sqrt{v_{a r}} & \text { if } \quad 2.38 \cdot\left|T_{c l}-T_{a}\right|^{0.25}<12.1 \cdot \sqrt{v_{a r}}\end{cases} \\
& f_{c l}= \begin{cases}1.00+1.290 \cdot I_{c l} & \text { if } \quad I_{c l} \leq 0.078 \\
1.05+0.645 \cdot I_{c l} & \text { if } \quad I_{c l}>0.078\end{cases}
\end{aligned}
$$

$I_{c l}=0.078\left(\mathrm{~m}^{2} \mathrm{~K} / \mathrm{W}\right)$ is the common clothing insulation in summer [26] and $v_{a r}=0.4 \mathrm{~m} / \mathrm{s}$ is the relative air velocity [27]. Equation 9 together with Eq. 10 were solved for $T_{c l}$, using an iterative method in each time step. Moreover, since the surfaces' temperatures were not significantly different from each other, the mean radiant temperature $\left(\bar{T}_{r}\right)$ was assumed as the area-weighted average temperature of the internal surfaces of the bus body (top, floor, windows, and sides) [21].

PMV index is classified into seven thermal sensation scales, as: \pm 3 (hot/cold), \pm 2 (warm/cool), \pm 1 (slightly warm/cold), and 0 (neutral). According to ISO7730:2005 [28] and as Table 3 shows there are three satisfaction classes based on the PMV, ranged from the highest satisfaction level (Class A ) to the least and basic level (Class C).

Table 3: Thermal comfort classes according to ISO7730:2005 [28]

\begin{tabular}{ccc}
\hline Class & PMV range & PPD range \\
\hline $\mathrm{A}$ & $-0.2<P M V<0.2$ & $P P D<6$ \\
$\mathrm{~B}$ & $-0.5<P M V<0.5$ & $P P D<10$ \\
$\mathrm{C}$ & $-0.7<P M V<0.7$ & $P P D<15$ \\
\hline
\end{tabular}

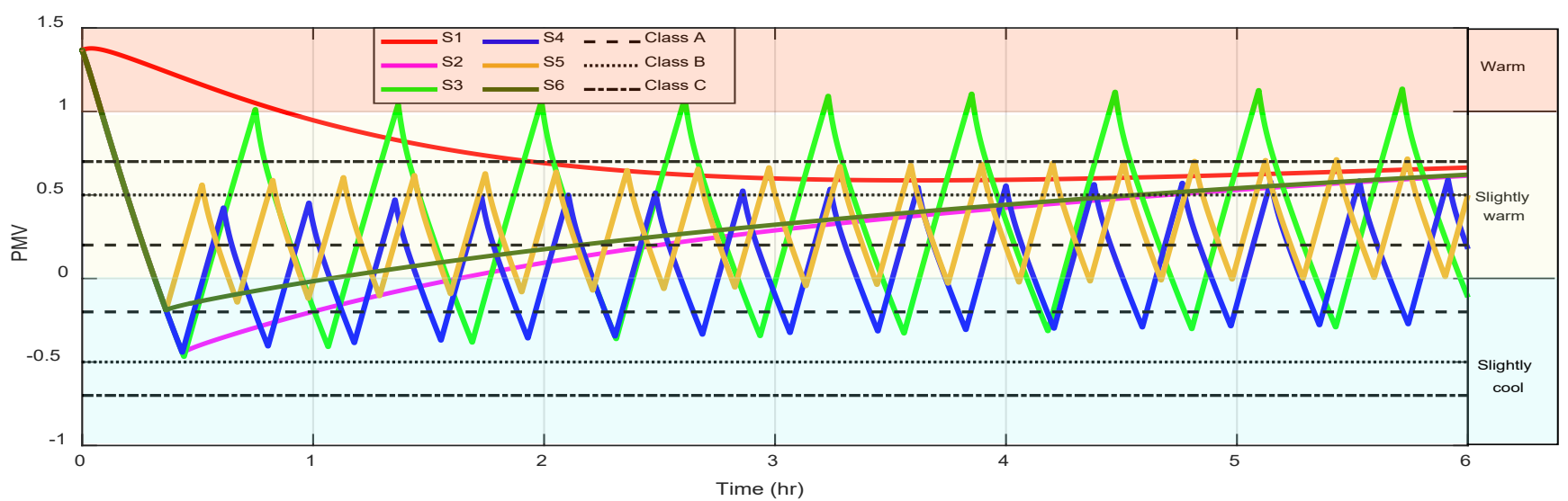

Fig. 7: Real-time PMV for different control strategies, the thermal sensation scales associated to PMV are colored and indicated on the right axis. 


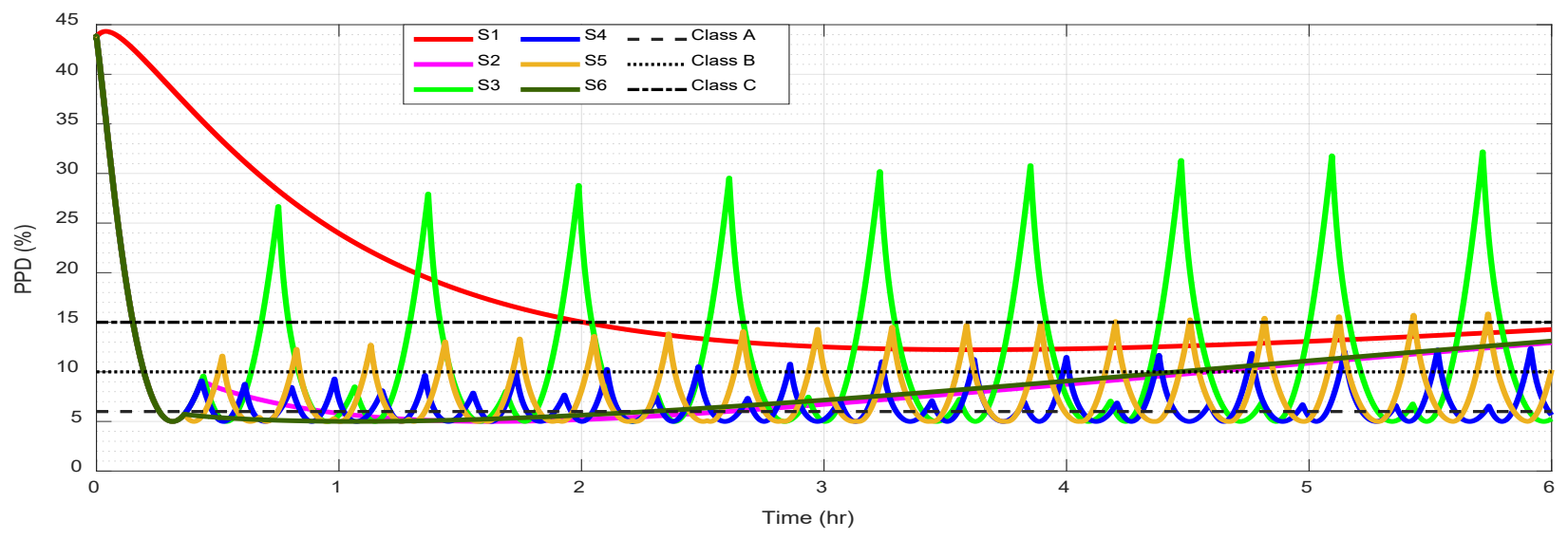

Fig. 8: Real-time PPD for different control strategies and thermal comfort classes.

Fig. 7 shows how PMV changes inside the bus cabin over six hours by implementing six different control strategies, S1 to S6. In this study, the acceptable comfort class is Class B as the moderate comfort range for indoor spaces, according to Table 3. However, this range is not strict and a broader span of PMV in Class C could be selected as the basic thermal comfort level, depending on the application and trade-off policy between the energy consumption and comfort level. Fig. 8 demonstrates the PPD, as another informative index for quantifying the discomfort level, with its thresholds for the comfort zones. In addition, Table 4 shows the duration (\%) that the thermal comfort of the cabin met the thermal comfort classes, under different control strategies. As Fig. 7 and Fig. 8 depict, S1 is not a proper strategy for high and moderate comfort levels as it cannot reach the PMV/PPD thresholds of Class A and B. Under this strategy just one compressor operated all the time and the $\mathrm{AC}$ system cooling capacity would not suffice to remove the cabin thermal load; however, if a wider range (Class $\mathrm{C}$ ) was considered as the comfort zone, it would meet the thermal requirement, albeit after about two hours. In fact according to Table $4,32.4 \%$ of the total time the thermal comfort is out of range, followed by $67.6 \%$ laying in Class C. As Fig. 7 and Fig. 8 demonstrate, S3 shows an improper thermal comfort control behaviour as well. Under this strategy, both the AC units operated together to keep the cabin temperature between the upper and lower temperature thresholds $\left(23<T_{c a b}<27^{\circ} \mathrm{C}\right)$. In contrast to $\mathrm{S} 1$, even though the $\mathrm{AC}$ system cooling capacity (operating under $\mathrm{S} 3$ ) is high enough to remove the thermal load, the PMV exceeds all the comfort zones (even Class $\mathrm{C}$ ), due to the higher temperature threshold $\left(T_{u}\right)$ and the humidity accumulation inside the cabin. Based on Table 4, the thermal comfort condition of the cabin was out of the range at $23.4 \%$ of the total time; however, it could satisfy both Classes B and A at 62.8 and $29.6 \%$, respectively. Under the adopted operating conditions, both S2 and S6 show the same trend where in both cases the AC system started with two units to reach the comfort criteria inside the cabin and the second unit went off afterwards. Under the selected conditions and for S2, the second unit did not go on again because the DI did not exceed its threshold $\left(24^{\circ} \mathrm{C}\right)$. Likewise for $\mathrm{S} 6$, the second unit did not go on as the cabin temperature did not reach its upper threshold that was $27^{\circ} \mathrm{C}\left(\Delta \mathrm{T}_{2}= \pm 2^{\circ} \mathrm{C}\right)$. According to Fig. 7 and Fig. 8 both S2 and S6 exceed Class A, partially satisfy Class B, and fully meet the requirement of Class C. As Table 4 shows, S2 performed slightly better than S6 to satisfy Class B. For the AC system operating under S4 and S5 the PMV trends are similar as well. In these situations, both units operated simultaneously but within different control criteria. Here, S4 controlled both AC units to operate within the discomfort level $\left(21<D I<24^{\circ} \mathrm{C}\right)$. S5 strategy was similar to S3 where the set point temperature was $25^{\circ} \mathrm{C}$ but applied a fixed margin of $\pm 1^{\circ} \mathrm{C}$ (instead of $\pm 2^{\circ} \mathrm{C}$ in S3). Again as Fig. 7 and Table 4 show, both S4 and S5 exceed Class A and are almost bounded within the limits of the Class C, with an oscillating behaviour which is different form S2 and S6. Furthermore, S4 satisfies the Class B requirements at $93.4 \%$ of the total time, while S5 meets the conditions at $79 \%$.

Table 4: Time percentage of the thermal comfort classes' fulfilment inside the cabin under different control strategies

\begin{tabular}{lcccc}
\hline Strategy & Class A (\%) & Class B (\%) & Class C (\%) & Out of range (\%) \\
\hline S1 & 0.0 & 0.0 & 67.6 & 32.4 \\
S2 & 26.7 & 75.0 & 97.5 & 2.5 \\
S3 & 29.6 & 62.8 & 76.6 & 23.4 \\
S4 & 46.9 & 93.4 & 97.5 & 2.5 \\
S5 & 37.8 & 79.0 & 97.3 & 2.7 \\
\hline
\end{tabular}




\begin{tabular}{llll}
\hline S6 & 31.4 & 72.9 & 97.5
\end{tabular}$\quad 2.5$

Fig. 9 shows the overall heat flux removed from the cabin through the evaporators, for three more distinctive scenarios (i.e., S1, S4, and S6). This figure clearly demonstrates that the cooling capacity under S1 is less than the other strategies. Here the blue line implies the oscillating behaviour of the AC system (S4), alternating between On and Off states. According to this figure the maximum cooling capacity of the AC system when working with one unit (S1) is about $13.5 \mathrm{~kW}$ and with two units is about $27 \mathrm{~kW}$. It worth noting that the cooling capacity at the beginning of conditioning process is slightly higher which is due to the higher initial cabin temperature, as shown in Fig. 10.

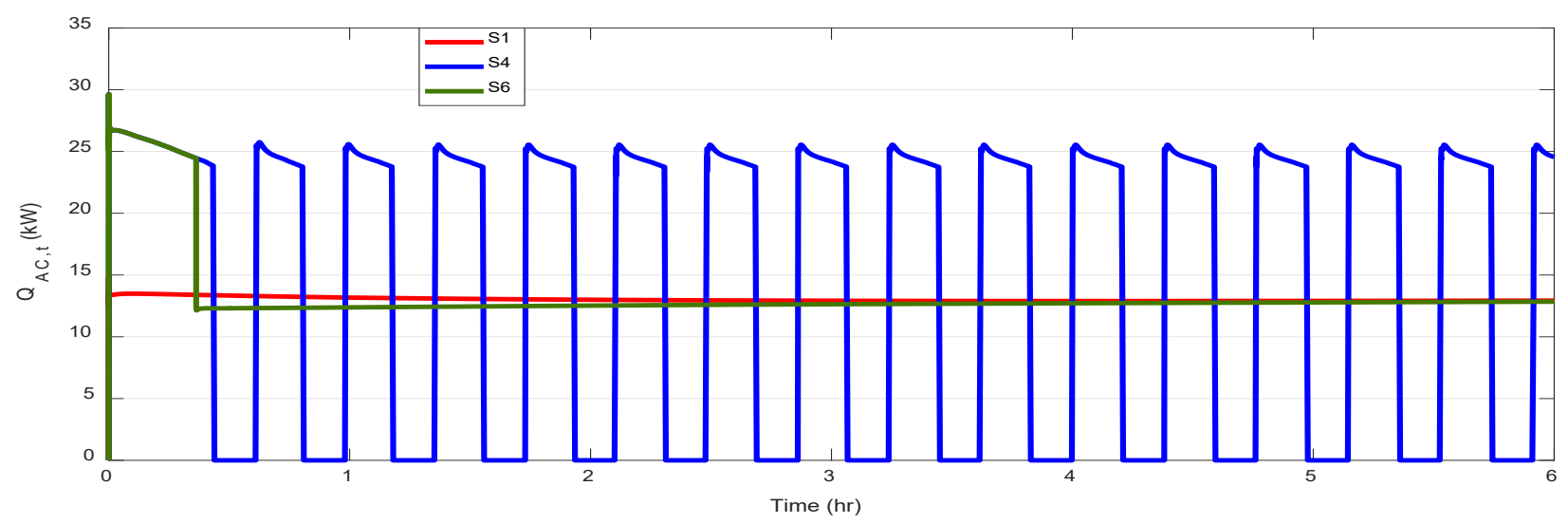

Fig. 9: Cooling capacity for different control strategies implementation.

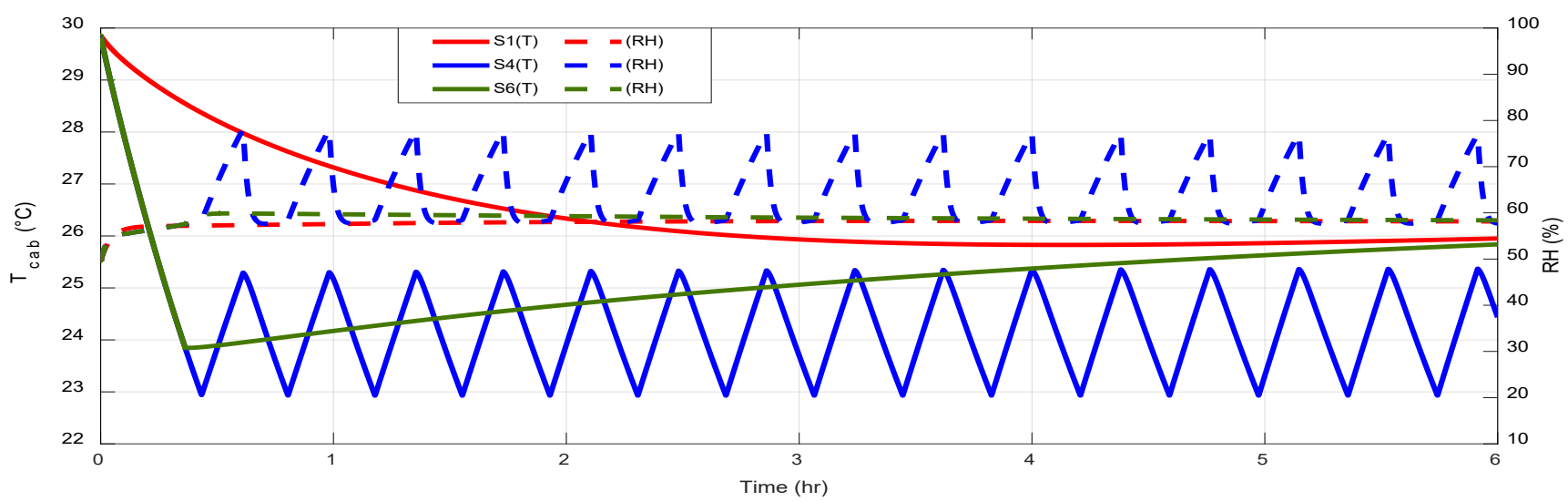

Fig. 10: Real-time $T_{\text {cab }}$ and RH for different control strategies.

Fig. 10 demonstrates the average cabin temperature and relative humidity for the selected control strategies. As it is clear the average temperature under S1 implementation is the highest while for S4 is the lowest. Furthermore, the RH under S1 and S6 remains below 60\% while for S4 oscillates between 57 and $78 \%$. This oscillating behaviour is a result of the continuous humidity production (by passengers) and condensation on the evaporators.

In order to facilitate the comparison between different control strategies, implemented in this study, we introduce the time-averaged overall power $\left(W_{a v}\right)$, Coefficient of Performance $\left(C O P_{a v}\right)$, and Predicted Percentage of Dissatisfied $\left(P P D_{a v}\right)$ as follows:

$$
\begin{aligned}
& W_{a v}=\sum_{i=1,2} \int_{t_{0}}^{t}\left(\dot{m}_{r, i} \cdot\left(h_{\text {comp }, i, \text { out }}-h_{\text {comp }, i, \text { in }}\right) / \eta_{\text {comp }}+W_{f, i}+W_{b l, i}\right) d t / t \\
& \dot{Q}_{a v}=\sum_{i=1,2} \int_{t_{0}}^{t} \dot{m}_{r, i} \cdot\left(h_{e, i, o u t}-h_{e, i, i n}\right) d t / t \\
& C O P_{a v}=\dot{Q}_{a v} / W_{a v}
\end{aligned}
$$




$$
P P D_{a v}=\int_{t_{0}}^{t} P P D d t / t
$$

Here $i$ represents the AC unit, $h_{\text {comp }}$ is the specific enthalpy of the refrigerant R134a passing through the compressor, $\eta_{\text {Comp }}$ is the compressor's efficiency, $W_{f}$ and $W_{b l}$ are the power of the fan and blower of each unit. Fig. 11 shows how implementing different control strategies affects $W_{a v}, C O P_{a v}$, and $P P D_{a v}$ under the adopted operating conditions. This figure helps to have a better understanding on the time-averaged energy consumption, efficiency, and discomfort level, when we need to adopt a proper control strategy to strike a balance between the costs and comfort level. As it is evident the least needed power belongs to S1 where just one unit operated with the highest $C O P_{a v}$ that is desirable from the cost point of view; however, this strategy suggests the highest discomfort level, which is out of the thermal comfort range, as well. Among the implemented strategies, S3 shows the second lowest $C O P_{a v}$, second highest $W_{a v}$ and $P P D_{a v}$, which is in line with the results shown in Fig. 8. As this figure depicts, $\mathrm{S} 4$ demands the highest power compared to $\mathrm{S} 1$ with about an additional $10 \%$ and shows the lowest $P P D_{a v}(=7 \%)$. The other strategies, i.e., S2, S5, and S6, respectively demand about 5.5, 5.8, and $4.5 \%$ more power in comparison with $\mathrm{S} 1$ while all offer $P P D_{a v}<10$ (Class B).

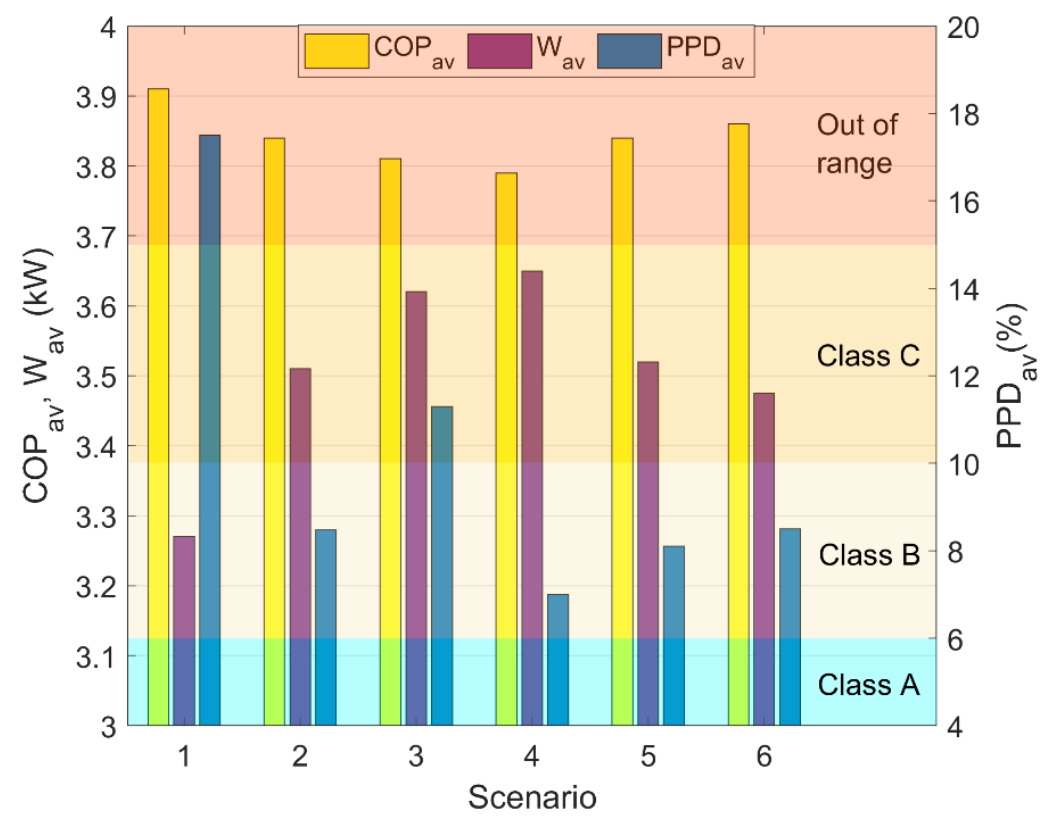

Fig. 11: $W_{a v}, C O P_{a v}, P P D_{a v}$ under different control strategies. The coloured zones Illustrate the associated thermal comfort classes with their $P P D_{a v}$ (bars in matte blue).

\section{Conclusion}

In this paper, Simulink/Simscape toolbox from MATLAB (R2019a) was used to build up a dynamic model of a multi-unit air conditioning system of a generic bus. One sub-model for the recirculated moist air inside the cabin with an associated thermal network, and one for the phase-changing refrigerant flow inside a refrigeration cycle were coupled to form this model. The performance of the AC system and the thermal comfort for arbitrary ambient and operational conditions were investigated by implementing different control strategies, namely S1 to S6. It was revealed that the control criteria affected the thermal comfort level and the needed power, remarkably. As results indicated under the adopted ambient and part-load operational conditions, we can conclude that:

- Using just one unit, S1, needs the least power and suggests the highest COP; however, the cooling capacity would not be enough to meet the thermal comfort level.

- Adopting the same set-point temperature with different margins $\left(\Delta_{1} T= \pm 1, \Delta_{2} T= \pm 2{ }^{\circ} \mathrm{C}\right)$ for the AC units (S6) shows the lowest needed power (only $4.5 \%$ more than S1), while the time-averaged Predicted Percentage of Dissatisfied index lies in the Class B and meets the requirements of the moderate thermal comfort. 
- S4, where both units operated simultaneously based on the acceptable range of DI, is the most conservative strategy by offering the lowest $P P D_{a v}(=7 \%)$; however, it demands the highest power for the compressors, fans, and blowers with an additional 10\% compared with $\mathrm{S} 1$.

- $\mathrm{S} 2$ and S5 show almost the same $P P D_{a v}, C O P_{a v}$, and $W_{a v}$, while $\mathrm{S} 2$ offered better thermal comfort control with less oscillating behaviour.

- In $\mathrm{S} 3$, increasing the temperature margin by $1^{\circ} \mathrm{C}$ (with respect to $\mathrm{S} 5$ ) slightly reduced the power by $3 \%$ but increased the $P P D_{a v}$ from 8 to 11, where the Class B criterion is not met anymore. In addition, the cabin PMV was out of the range at $23.4 \%$ of the total time.

It is worth noting that the best strategy depends on the adopted trade-off policy between energy costs and comfort level. The reader should bear in mind that the current study is limited to model a baseline multi-unit AC system with a simplified cabin, working under a specific partial-load. Notwithstanding these limitations, the study suggests a potential framework to simulate complex AC systems and predict their dynamic response to the real-time changes in sensible and latent thermal loads. This study also offers efficient control strategies to provide passengers with an acceptable comfort level. Further investigation and experimentation on different control strategies, events, operational conditions, and systems' architecture is strongly recommended.

\section{Acknowledgments:}

This work was supported by the Northern Ireland Department for the Economy (DfE), Innovate UK and Wrightbus

\section{References}

[1] A. Behravan, R. Obermaisser and A. Nasari, "Thermal dynamic modeling and simulation of a heating system for a multi-zone office building equipped with demand controlled ventilation using MATLAB/Simulink," in International Conference on Circuits, System and Simulation (ICCSS), 2017. DOI: 10.1109/CIRSYSSIM.2017.8023191.

[2] D. Marcos, F. J. Pino, C. Bordons and J. J. Guerra, "The development and validation of a thermal model for the cabin of a vehicle," Applied Thermal Engineering, vol. 66, no. 1-2, pp. 646-656., 2014. DOI: 10.1016/J.APPLTHERMALENG.2014.02.054.

[3] Y. Huang, A. Khajepour, F. Bagheri and M. Bahrami, "Modelling and optimal energy-saving control of automotive air-conditioning and refrigeration systems," Proceedings of the Institution of Mechanical Engineers, Part D: Journal of Automobile Engineering, pp. 231(3), 291-309, 2017. DOI:10.1177/0954407016636978.

[4] J. Li and P. Hrnjak, "Improvement of condenser performance by phase separation confirmed experimentally and by modeling," International journal of refrigeration, vol. 78, pp. 60-69, 2017.

[5] E. Afrasiabian, O. Iliev, I. Shklyar, S. Lazzari and F. Boero, "Investigation on the Performance of a Compact Three-Fluid Combined Membrane Contactor for Dehumidification in Electric Vehicles," Energies, vol. 12, no. 9, p. 1660, 2019. DOI:10.3390/en12091660.

[6] Ş. Ünal, "An Experimental Study on a Bus Air Conditioner to Determine its Conformity to Design and Comfort Conditions," Journal of Thermal Engineering, vol. 3, no. 1, pp. 1089-1101., 2016.

[7] X. Ma, Z. Han, Q. Liu, X. Ju, J. Liu and S. Zhang, "Performance Simulation on the air conditioning system based on low-grade energy-bus," Procedia Engineering, pp. 205, 2463-2469., 2017. 
[8] H. He, M. Yan, C. Sun, J. Peng, M. Li and H. Jia, "Predictive air-conditioner control for electric buses with passenger amount variation forecast," Applied energy, pp. 227, 249-261, 2018. DOI:

10.1016/j.apenergy.2017.08.181.

[9] Y. Mao, J. Wang and J. Li, "Experimental and numerical study of air flow and temperature variations in an electric vehicle cabin during cooling and heating," Applied Thermal Engineering, vol. 137, pp. 356367, 2018. DOI: 10.1016/j.applthermaleng.2018.03.099.

[10] C. J. Yang, T. C. Yang, P. T. Chen and K. D. Huang, "An Innovative Design of Regional Air Conditioning to Increase Automobile Cabin Energy Efficiency," Energies, pp. 12(12), 2352., 2019. DOI: 10.3390/en12122352.

[11] S. Khatoon and M. H. Kim, "Human thermal comfort and heat removal efficiency for ventilation variants in passenger cars," Energies, pp. 10(11), 1710., 2017. DOI: 10.3390/en10111710.

[12] Fayazbakhsh, M. Ali and M. Bahrami, "Comprehensive modeling of vehicle air conditioning loads using heat balance method," SAE Technical Paper, pp. No. 2013-01-1507, 2013. DOI: 10.4271/2013-01-1507.

[13] Modares, F. Ghadiri and R. Soltani, "Multi-Zone Dynamic Modeling of Thermal Behavior in Vehicle's Cabin for Comfort and Energy Saving," SAE Technical Paper, pp. No. 2019-01-5060., 2019. DOI: 10.4271/2019-01-5060.

[14] B. Torregrosa-Jaime, F. Bjurling, J. M. Corberán, F. Di Sciullo and J. Payá, "Transient thermal model of a vehicle's cabin validated under variable ambient conditions," Applied Thermal Engineering, pp. 75, 4553., 2015. DOI: 10.1016/j.applthermaleng.2014.05.074.

[15] H. Lee, Y. Hwang, I. Song and K. Jang, "Transient thermal model of passenger car's cabin and implementation to saturation cycle with alternative working fluids," Energy, pp. 90, 1859-1868., 2015. DOI: 10.1016/j.energy.2015.07.016.

[16] T. Kiss, L. Chaney and J. Meyer, "New Automotive Air Conditioning System Simulation Tool Developed in MATLAB/Simulink," SAE Int. J. Passeng. Cars - Mech. Syst., pp. 6(2):826-840, 2013. doi:10.4271/2013-01-0850.

[17] Y. Huang, A. Khajepour, H. Ding, F. Bagheri and M. Bahrami, "An energy-saving set-point optimizer with a sliding mode controller for automotive air-conditioning/refrigeration systems," Applied energy, pp. 188, 576-585, 2017. DOI: 10.1016/j.apenergy.2016.12.033.

[18] S. Schaut and O. Sawodny, "Thermal Management for the Cabin of a Battery Electric Vehicle Considering Passengers' Comfort," IEEE Transactions on Control Systems Technology., 2019. DOI: 10.1109/TCST.2019.2914888.

[19] MATLAB, version 9.3 (R2019a), Natick, Massachusetts: The MathWorks Inc., 2018.

[20] C. Sanders, "Final Report Annex 24, Volume 2, Environmental Conditions," International Energy Agency, Leuven, Belgium, 1996.

[21] R. H. Howell, W. J. Coad and J. Harry J. Sauer, Principles of heating ventilating and air conditioning, 7th edition, Atlanta, GA : ASHRAE, (C2013. 
[22] W. Zhang and J. Liu, "Investigation on the Temporal Surface Thermal Conditions for Thermal Comfort Researches Inside A Vehicle Cabin Under Summer Season Climate," MATEC Web of Conferences, vol. 51, p. 03004, 2016. DOI: 10.1051/matecconf/20165103004.

[23] E. C. Thom, "The discomfort index.," Weatherwise, vol. 212, no. 2, pp. 57-61, 1959.

[24] C. G. Helmis, V. D. Assimakopoulos, H. A. Flocas, O. I. Stathopoulou, G. Sgouros and M. Hatzaki, "Indoor air quality assessment in the air traffic control tower of the Athens Airport, Greece," Environmental monitoring and assessment, pp. 148(1-4), 4, 2009. DOI: 10.1007/s10661-007-0138-9.

[25] P. Fanger, Thermal Comfort., Robert E. Krieger, Malabar, FL., 1982.

[26] ANSI/ASHRAE Standard 55-2017, Thermal Environmental Conditions for Human Occupancy, 2017.

[27] R. Musat and E. Helerea, "Parameters and models of the vehicle thermal comfort," Acta Universitatis Sapientiae, Electrical and Mechanical Engineering, pp. 1, 215-226., 2009.

[28] ISO7730:2005, Ergonomics of the thermal environment-analytical determination determination and interpretation of thermal comfort using calculation of PMV and PPD indices and local thermal comfort criteria, Internation Organization for Standardization, 2005.

\section{Nomenclature}

$\begin{array}{ll}C_{D} & \text { Discharge coefficient } \\ c_{p} & \text { Specific heat, } J \cdot \mathrm{kg}^{-1} \cdot \mathrm{K}^{-1} \\ d & \text { Diameter, } \mathrm{m} \\ f_{c l} & \text { Clothing surface area factor } \\ I_{c l} & \text { Clothing insulation, } \mathrm{m}^{2} \cdot \mathrm{K} \cdot \mathrm{W}^{-1} \\ I^{\prime} & \text { Solar irradiance, } W \cdot \mathrm{m}^{-2} \\ k & \text { Heat transfer coefficient, } W \cdot \mathrm{m}^{-2} \cdot \mathrm{K}^{-1} \\ L & \text { Thickness and Length, } \mathrm{m} \\ M & \text { Metabolic rate, } W \cdot \mathrm{m}^{-2} \\ m & \text { Mass, } \mathrm{kg} \\ \dot{m} & \text { Mass flow rate, } \mathrm{kg} \cdot \mathrm{s}^{-1} \\ N_{\text {row }} & \text { Number of tube rows perpendicular to } \\ & \text { the air flow direction } \\ N_{t u} & \text { Number of tube turns in the air flow } \\ & \text { direction } \\ p_{v a} & \text { Water vapour partial pressure, } P a \\ \mathrm{RH} & \text { Relative humidity } \\ S & \text { Surface area, } \mathrm{m}^{2} \\ T & \text { Temperature, }{ }^{\circ} \mathrm{C}\end{array}$

\begin{tabular}{|ll}
$\bar{T}_{r}$ & Mean radiant temperature, ${ }^{\circ} \mathrm{C}$ \\
$t$ & Time, $s$ \\
$V$ & Volume, $m^{3}$ \\
$v_{a r}$ & Relative air velocity, $m \cdot s^{-1}$ \\
$W$ & Power, $W$ \\
& Subscripts \\
$a$ & Air \\
$a m b$ & Ambient \\
$a v$ & Average \\
$b$ & Bus body \\
$b l$ & Blower \\
$c$ & Condenser \\
cab & Cabin \\
$c l$ & Clothing surface \\
comp & Compressor \\
cond & Conduction \\
conv & Convection \\
$e$ & Evaporator \\
ext & External
\end{tabular}

\begin{tabular}{|ll}
$f$ & Fan \\
int & Internal \\
$l$ & Latent \\
met & Metabolic \\
pas & Passenger \\
$r$ & Refrigerant \\
s & Sensible \\
set & Set-point \\
sol & Solar \\
sub & Sub-cooling \\
sup & Super-heating \\
vent & Ventilation \\
win & Windows \\
& Greek symbols \\
$\alpha$ & Transmissivity \\
& coefficient \\
$\eta$ & Efficiency \\
$\rho$ & Density, $k g / \mathrm{m}^{3}$ \\
$\tau$ & Absorptivity
\end{tabular}

